\title{
The Dynamic and Incremental Features of Vocabulary Acquisition
}

\author{
Thamer Alharthi ${ }^{1}$ \\ ${ }^{1}$ Department of European Languages and Literature, King Abdulaziz University, Jeddah, Saudi Arabia \\ Correspondence: Thamer Alharthi, P. O. BOX 80200, Jeddah 21589, Saudi Arabia. E-mail: talharthi@kau.edu.sa
}

\author{
Received: October 13, 2014 Accepted: November 2, 2014 Online Published: November 25, 2014 \\ doi:10.5539/ijel.v4n6p70 URL: http://dx.doi.org/10.5539/ijel.v4n6p70
}

\begin{abstract}
Considering the wealth of research on second and foreign language vocabulary learning, it is well established and documented that vocabulary knowledge is dynamic and incremental in nature. While some aspects of vocabulary knowledge might be mastered in a short period of time, others need a long time to be established, and longitudinal research could provide insights into precisely how language learners approach vocabulary learning, both within and beyond the classroom. The present article reviews the recent literature on the development of vocabulary knowledge, drawing on the three major types of vocabulary knowledge: breadth (how many words of the target language learners know), depth (what the learners know about the target words) and degree of mastery of receptive and productive vocabulary knowledge. The findings reported in these studies revealed that the process of acquiring vocabulary knowledge is not only complicated but that multiple knowledge dimensions are gradually learned and sooner than others.
\end{abstract}

Keywords: vocabulary, longitudinal, incremental, breadth, depth, receptive and productive knowledge

\section{Introduction}

The literature has identified that vocabulary learning is incremental in nature, as the mastery of a word is gradual and the learner needs to be exposed to it many times (Henriksen, 1999; Hirsch, 2003; Hunt \& Beglar, 2005; Joe, 2010; Nagy, Anderson, \& Herman, 1987; Nagy \& Scott, 2000; Nation, 2001; Schmitt, 1998, 2000, 2010; Stahl, 2009). Achieving mastery of second language vocabulary requires the learner to undergo a complicated process of a comprehensive understanding of different aspects of vocabulary knowledge such as form, meaning and use (Nation, 2001; Richards, 1976; Schmitt, 2000). However, complete mastery of the different facets of vocabulary knowledge cannot be achieved through a limited number of contexts and exposures. This is because "vocabulary learning is not an all-or-nothing piece of learning but is rather a gradual process of one meeting with a word adding to or strengthening the small amount of knowledge gained from previous meetings" (Nation, 2001, p. 155).

According to Henriksen (1999), the incremental nature of acquiring vocabulary knowledge can be described in three components: breadth of vocabulary knowledge (partial/precise knowledge of known words in the target language), depth of vocabulary knowledge (how well are words known in regard to meaning and use), and use of receptive and productive vocabulary knowledge. This paper provides a thorough discussion of the incremental nature of vocabulary knowledge, organised in terms of these three dimensions, and drawing on relevant research in $\mathrm{L} 2$ and FL contexts.

\section{Breadth of Vocabulary Knowledge}

The breadth of vocabulary knowledge refers to the size or quantity of vocabulary which is partially or fully known by learners (Henriksen, 1999; Qian, 1999, 2002, 2004). It is considered a continuum, ranging from partial to full knowledge (Henriksen, 1999; Schmitt, 1998, 2000). Moreover, Schmitt (2000) suggests that all vocabulary knowledge can be ranged on a cline as being not known-partially-fully known applying this to spelling, as shown in Figure 1:

$\begin{array}{llll}\text { can't spell } & \text { knows some } & \text { phonologically } & \text { fully correct } \\ \text { word at all } & \text { letters } & \text { correct } & \text { spelling }\end{array}$

Figure 1. Aspects of lexical knowledge ranging from zero to partial to precise (adopted from Schmitt, 2000, p. 118) 
Milton (2006) investigated the annual growth of the vocabulary size of British learners of French up to graduation from a language school. His study offered a good example of documenting the incremental development of lexical knowledge over time, particularly at the beginning stages of the learning process. $\mathrm{He}$ used a French vocabulary size test which incorporated Baudot's (1992) frequency levels. The test took a paper and pencil form and comprised 120 Yes/No answers to whether the learners know the word or not. The time of completing the test was not restricted; however, it was usually completed within 5 to 10 minutes. Moreover, 20 unreal words were added to the test and 20 real words were chosen randomly for every 1000 word level out of 5,100 frequency word bands. The number of Yes answers to real words was adjusted to minimize guessing.

As suggested by Milton, the results show that while learners of French advance from one school year to another so does their vocabulary size (Figure 2). While year 7 learners' mean score was 311, the score of year 13 learners had increased to 1930. Furthermore, an ANOVA test confirmed a significant $(F=98.579, p<.001)$ relationship between the increase in vocabulary breadth and the time the learners spent on learning. Consequently, Milton's (2006) study thus provided further support for the notion of a gradual or incremental increase in vocabulary size by EFL learners.

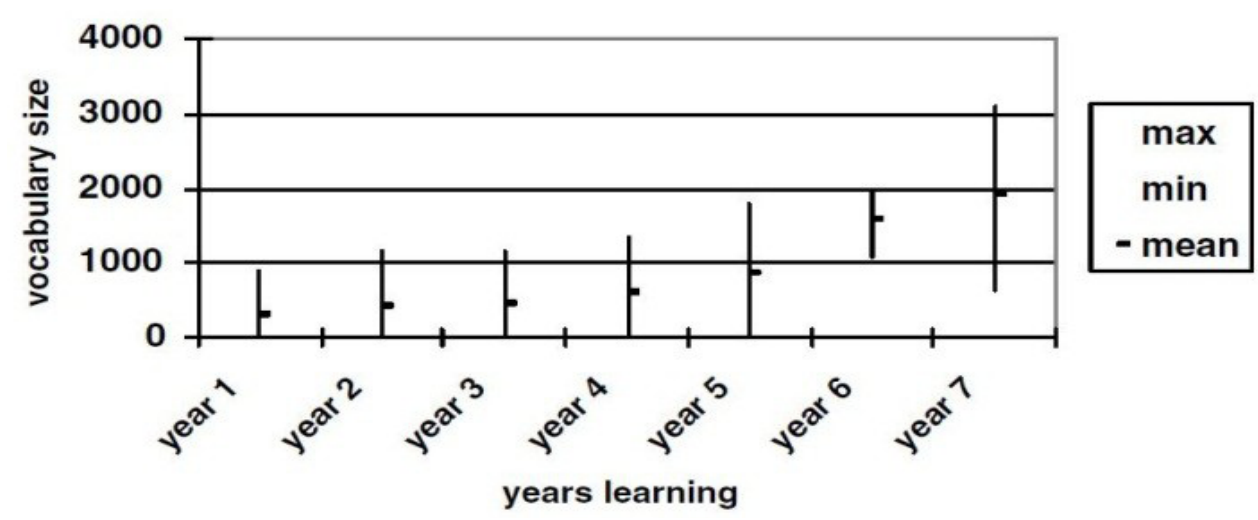

Figure 2. Annual progress in frequency bands at school level (adopted from Milton 2006, p. 192)

More recently, Gallego \& Llach (2009) in a longitudinal study tracked the gradual increase in receptive vocabulary knowledge of 224 young Spanish learners of EFL. The goal of the study was to measure the learners' receptive vocabulary size growth over a period of four years and to check the effect of target language exposure on the learners' vocabulary knowledge size. The study incorporated the $2 \mathrm{k}$ frequency level of Schmitt, Schmitt and Clapham (2001, version 2) Vocabulary Levels Test. Starting with an exposure of 419 target language interaction hours in 4th grade, learners had 524, 629 and 734 target language interactions in their 5th, 6th and 7th grade, respectively.

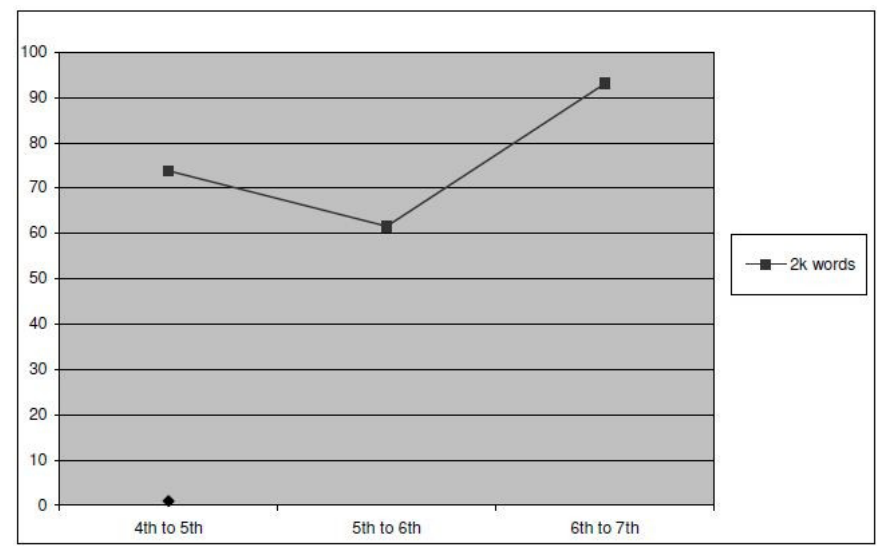

Figure 3. Evolution of the increment of word knowledge (adapted from Gallego \& Llach, 2009, p. 124) 
They found that the learners' receptive vocabulary knowledge size grew significantly $(p<.001)$ as they moved from one grade to another (Figure 3). In relation to the $2 \mathrm{k}$ frequency level, the learners added 148 words from 4th to 5 th grade, 122 words from 5th to 6 th grade, and 186 words from 6th to 7 th grade to their receptive vocabulary knowledge. We conclude from these results that vocabulary learning is incremental in terms of an adequate vocabulary size.

\section{Depth of Vocabulary Knowledge}

Depth of vocabulary knowledge refers to how well a learner knows a word (Qian, 1999, 2002) in terms of several lexical aspects such as form, meaning and use (Nation, 2001).

One of the few longitudinal studies that sheds more light onto the incremental nature of increasing the depth of vocabulary knowledge was that of Schmitt (1998). His study tracked three advanced L2 university students' knowledge of 11 words over the course of one academic year with respect to spelling, associations, grammatical information and meaning. Schmitt conducted three interviews where he used different measurements for each knowledge type: writing for a test for spelling, providing three words in response to a target word stimulus for association and knowing the target word's word class and use for grammatical information. The results of the learners' scores are presented in Table 1 below.

Table 1. The development of vocabulary knowledge over time (adapted from Schmitt, 1998, pp. 296-299)

\begin{tabular}{llllllllll}
\hline & \multicolumn{1}{c}{ Results } \\
\hline & Spelling & \multicolumn{9}{c}{ Association } & \multicolumn{3}{c}{ Grammar } \\
\hline Participants & Time1 & Time2 & Time 3 & Time1 & Time2 & Time3 & Time1 & Time2 & Time 3 \\
Lith & 2.64 & 2.73 & 2.91 & 1.09 & 1.73 & 2.09 & 2.45 & 2.09 & 2.91 \\
Ind & 2.82 & 2.73 & 2.73 & 1.64 & 1.55 & 1.73 & 2.09 & 2.63 & 1.64 \\
Thi & 2.55 & 2.91 & 3.00 & 1.09 & 2.00 & 2.18 & 1.82 & 2.36 & 3.36 \\
\hline
\end{tabular}

The results of spelling test show that learners have improved their spelling across the study period. Schmitt explains that the learners had little problems regarding spelling even when they did not know the meaning of words. As a result, he suggests that spelling might be one of the first acquired aspects of vocabulary knowledge. Moreover, learners' scores for associations indicate a gradual improvement as they become more native-like over time. Regarding the grammatical information aspect, only one participant shows a steady growth in grammatical knowledge which might be due to the fact that this participant spent extra time looking up words in the dictionary (Schmitt, 1998).

The development of the word knowledge types does not follow a particular order rather some knowledge aspects seem to develop before others (Schmitt, 1998, 2000, 2010). Moreover, mastery of nouns and verbs seems to come before adjectives and adverbs (Table 2). Accordingly, the current study highlights the incremental nature of the depth of vocabulary knowledge where learners become more proficient in learning the target language over time.

Table 2. Number of words known in each word class (adapted from Schmitt, 1998, p. 308)

\begin{tabular}{lllllllll}
\hline & Noun & & \multicolumn{2}{c}{ Verb } & \multicolumn{3}{c}{ Adjective } & Adverb \\
\hline & $\mathrm{n}$ & $\%$ & $\mathrm{n}$ & $\%$ & $\mathrm{n}$ & $\%$ & $\mathrm{n}$ & $\%$ \\
\hline Lith $^{\mathrm{a}}$ & 30 & 91 & 33 & 100 & 11 & 33 & 8 & 24 \\
Ind $^{\mathrm{a}}$ & 21 & 64 & 28 & 85 & 6 & 18 & 13 & 39 \\
Tai $^{\mathrm{a}}$ & 30 & 91 & 31 & 94 & 10 & 30 & 11 & 33 \\
Kor $^{\mathrm{b}}$ & 10 & 91 & 10 & 91 & 7 & 64 & 1 & 9 \\
Total $^{\mathrm{c}}$ & 91 & 83 & 102 & 93 & 34 & 31 & 33 & 30 \\
\hline
\end{tabular}

Note. ${ }^{\mathrm{a}}$ Total $N=33,{ }^{\mathrm{b}}$ Total $\mathrm{N}=11,{ }^{\mathrm{c}}$ Total $\mathrm{N}=33$.

More heat than light has been generated with respect to the incremental learning of multiple word knowledge aspects through extensive reading. Pigada and Schmitt (2006) provide a good example to capture degrees of not only the knowledge of meaning but also other types of lexical knowledge such as spelling and grammatical characteristics. For this purpose, they conducted a case study of a 27-year old learner of French. The task was to read four graded readers with roughly a total of 30,000 words over a period of a month. The subject was given 133 words which contained 70 nouns and 63 verbs and was tested before and after the reading treatment. The 
pre- and post-tests of the learner's orthography, meaning and grammatical behaviour of words were done in a one-on-one interview similar to the measurement approach carried out by Schmitt (1998). The length of the spelling task was nearly 90 minutes while the administration of meaning and grammar tasks lasted two and a half hours.

The results suggest that extensive reading helped to improve aspects of vocabulary knowledge. There was considerable growth of the spelling part for all nouns and most verbs. That is, the learner at Time 1 scored 98 out of a total 266 spelling points, and higher with 159 out of 266 points at Time 2 . In the meaning facet, there was an improvement though to a lesser degree for both noun and verb classes. Specifically, the analysis of the interview revealed that the learner obtained scored 22 out of 266 at Time 1 and 63 out of 266 at Time 2. At the same time, the overall growth in grammatical knowledge was very small. The rate of nouns learned was 18 out of 142 at Time 1 but improved to 60 out of 142 at Time 2 . However, the number of verbs learned at Time 1 was only five out of 126 and 26 out of 126 at Time 2. It should be noted that Wilcoxon Signed Ranks tests showed significant gains of $p<.001$ in all types of word knowledge but especially in verb class.

Pigada and Schmitt (2006) concluded that extensive reading influenced the learner's growth in terms of orthography, meaning and grammatical types of lexical knowledge, "translating to a pick-up rate of about one of every 1.5 words tested" (p. 18). However, they were quick to warn that it was rather difficult to believe that the learner had complete mastery of these three types of word knowledge given that only $6 \%$ of the target words were learned. The researchers' contribution is valuable regarding the incremental development of vocabulary aspects of the learner when encountering new words in reading texts. We may conclude that Pigada and Schmitt's (2006) study has provided us with insights concerning the gradual process of learning vocabulary. That is, spelling was found to be improved before other facets of lexical knowledge such as meaning and grammatical mastery of words (Schmitt, 2010).

In the same manner, Webb (2007) conducted a study exploring the effect of multiple exposures on the depth of vocabulary knowledge. The study used ten tests to measure 121 learners' vocabulary knowledge aspects such as orthography, associations and the meaning-form link. The participants were Japanese university students of English in their second year; they had been learning English for at least seven years.

Prior to administering the tests the learners were divided into four groups and were then required to read a number of pages in a vocabulary reading comprehension task. The number of target words on each page was 1,3 , 7 and 10 for groups 1, 2, 3 and 4, respectively. The time of the task was controlled, depending on the number of target words that occurred in each group, where group 1 had four minutes, group 2 had 12 minutes, group 3 had 28 minutes, and group 4 had 40 minutes. Upon completion of the task, the members of the four groups took a surprise vocabulary test to compare the group scores in order to establish the effect of exposure on the development of vocabulary learning. The results suggest an overall growth in all aspects of vocabulary knowledge (Table 3). It is evident that the growth of vocabulary knowledge is dependent on the number of encounters with the target words in context, which further support provided by the effect of multiple exposures in the incremental process of vocabulary learning.

Table 3. table Means and standard deviations of learning conditons on dependent measures (adapted from Webb, 2007, p. 59)

\begin{tabular}{|c|c|c|c|c|c|c|c|c|c|}
\hline $\begin{array}{l}\text { Number of } \\
\text { encounters }\end{array}$ & 0 encounters & \multicolumn{2}{|c|}{1 encounter } & \multicolumn{2}{|c|}{3 encounters } & \multicolumn{2}{|c|}{7 encounters } & \multicolumn{2}{|c|}{10 encounters } \\
\hline Test & $N=22$ & \multicolumn{2}{|c|}{$N=23$} & \multicolumn{2}{|c|}{$N=26$} & \multicolumn{2}{|c|}{$N=26$} & \multicolumn{2}{|c|}{$N=22$} \\
\hline $\mathrm{PO}$ & $\begin{array}{ll}1.35 & 1.02\end{array}$ & 4.96 & 1.94 & 5.96 & 1.89 & 7.19 & 1.41 & 7.71 & 1.94 \\
\hline RO & & 6.70 & 1.72 & 8.00 & 1.30 & 8.27 & 1.51 & 8.75 & 1.03 \\
\hline PRM & & 0.35 & 0.65 & 1.31 & 1.81 & 2.65 & 2.77 & 2.88 & 2.40 \\
\hline PG & & 1.09 & 1.62 & 2.00 & 2.14 & 2.19 & 3.09 & 4.25 & 3.91 \\
\hline PS & & 0.91 & 1.62 & 1.46 & 1.92 & 2.31 & 2.72 & 3.67 & 3.46 \\
\hline $\mathrm{PA}$ & & 0.65 & 1.03 & 2.31 & 2.24 & 2.38 & 2.59 & 3.96 & 3.33 \\
\hline RG & & 5.65 & 1.67 & 6.81 & 1.77 & 7.04 & 2.07 & 7.96 & 1.97 \\
\hline $\mathrm{RS}$ & & 4.00 & 1.62 & 5.54 & 2.02 & 5.46 & 1.92 & 6.63 & 1.84 \\
\hline RA & & 4.78 & 1.76 & 5.69 & 2.05 & 5.58 & 2.23 & 6.88 & 2.40 \\
\hline RM & & 5.78 & 2.09 & 6.77 & 2.45 & 6.50 & 2.10 & 7.58 & 2.12 \\
\hline
\end{tabular}

Note. standard deviations are in standard deviations are in italics, Maximum score $1 / 410$, Key. PO $1 / 4$ productive knowledge of orthography; RO $1 / 4$ receptive knowledge of orthography; RRM $1 / 4$ receptive recall of meaning and form; RM $1 / 4$ receptive knowledge of meaning and form; $\mathrm{PA}^{1} / 4$ productive knowledge of association; RA $1 / 4$ receptive knowledge of association; PS $1 / 4$ productive knowledge of syntax; RS $1 / 4$ receptive 
knowledge of syntax; $\mathrm{PG}^{1} / 4$ productive knowledge of grammar; $\mathrm{RG}^{1} / 4$ receptive Knowledge of grammar.

\section{Use of Receptive and Productive Vocabulary Knowledge}

The idea of a dichotomy between receptive vocabulary and productive vocabulary has been globally accepted by most researchers. Hence, Melka (1997) points out the impossibility of having a clear and adequate definition to distinguish between the two notions. However, Melka (1997) provides a possible definition of receptive knowledge as the ability to understand vocabulary in reading and/or listening whereas productive knowledge is defined as the ability to use vocabulary in writing and/or speaking. The terms receptive vocabulary, passive vocabulary, reception and comprehension, active vocabulary, productive vocabulary and production are often used in discussions of receptive and/or productive language knowledge. Many researchers perceive receptive and productive vocabulary knowledge as being a continuum (Henriksen, 1999; Meara, 1996; Melka, 1997; Read, 2000; Schmitt, 2000, 2010). In addition, the relationship between these two aspects of lexical knowledge is said to prove to be of some difficulty. Yet in spite of the difference between receptive and productive word knowledge, it is commonly accepted by most researchers that the development of word knowledge proceeds from the receptive to the productive (see, for example, Channell, 1988; Waring 1997). Melka further suggests that learners incrementally move from receptive mastery to productive mastery as their lexical knowledge increases. However, it is difficult to decide on a threshold between receptive and productive mastery (Henriksen, 1999; Meara, 1997) and the amount of vocabulary needed to move from receptive to productive use (Read, 2000). This might be due to the influence of test types and lack of evidence of what constitute receptive and productive mastery (Schmitt, 2010).

In a cross-sectional study, Laufer (1998) examined the growth and relationship between receptive, controlled productive and free productive vocabulary knowledge over an interval of one year. The subjects in her study were 26 grade 10 and 22 grade 11 native speakers of Hebrew who studied English as a foreign language (EFL) for 6 and 7 years respectively. The students came from the same background and did not have native English-speaking parents. The study incorporated three different measurements: Vocabulary Level Test (Nation, 1983, 1990) for receptive knowledge, Controlled Productive Vocabulary Levels Test (Laufer \& Nation, 1999) for controlled productive knowledge, and Lexical Frequency Profile (Laufer \& Nation, 1995) for writing composition or free productive knowledge. All three tests were given in one week during normal class hours, with the first two tests taking about 20-30 minutes and the last test about 90 minutes to complete.

The results of these tests yielded some interesting results (Table 5). The growth of the learners' receptive knowledge is clearly impressive. It appears that the learners increased their receptive vocabulary knowledge by $84 \%$ as they moved from 10 th to 11 th grade. In other words, the results indicate that the learners gained about 1600 word in one year. Similarly, the controlled productive knowledge of the learners improved by about $50 \%$, gaining about 850 words in one year. On the other hand, the results from the free productive test did not reveal any significant growth. Therefore, both receptive and controlled productive vocabulary knowledge seemed to develop gradually over time, while the free productive ability seemed to lag behind.

Table 4. Vocabulary growth (adapted from Laufer, 1998, p. 263)

\begin{tabular}{llll}
\hline & Passive & Controlled active & Free active \\
\hline $10^{\text {th }}$ graders & 1.900 & 1.700 & $71 \%$ \\
$11^{\text {th }}$ graders & 3.500 & 2.550 & $67 \%$ \\
Gain in $\%$ & $84 \%$ & $50 \%$ & ---- \\
\hline
\end{tabular}

According to Laufer (1998), the relationship between receptive, controlled and free productive knowledge can be ascertained by examining the ratio between them. For receptive and controlled productive knowledge, the ratio is $89 \%$ in grade 10 while it goes down to $72 \%$ in grade 11 . Laufer suggests that such results could lead to the speculation that possessing high receptive vocabulary knowledge means further widening the gap with the controlled productive vocabulary knowledge. In other words, learners acquire a lot of vocabulary receptively and multiple exposures reinforce development of their receptive vocabulary knowledge, while they normally tend to use a number of the most frequent words and expressions in communication. Last but not least, the ratio between free productive vocabulary and other aspects of vocabulary knowledge is impossible to ascertain because the measurement was based on words' frequency not the subjects' knowledge of the word.

As informative as it might be, while this study highlights the growth of receptive and productive knowledge and compared the ratios obtaining between them, it did so without addressing the amount of vocabulary knowledge needed to move to productive use. As mentioned above in this section, this proves to be of some difficulty and 
requires further investigation.

Min (2008) attempted to explore the effectiveness of reading supplemented with vocabulary tasks versus reading only for vocabulary growth in an instructional setting. One of the research questions attempted to be answered in Min's study was whether reading instruction in combination with vocabulary focused activities or a narrow reading treatment would explain the incremental nature of receptive and productive vocabulary learning over a period of three months. The study involved 50 Chinese high school students in Taiwan. Participants were divided into two groups: experimental group $(\mathrm{n}=25)$ and control group $(\mathrm{n}=25)$.

The instruction treatments were given in five sessions of two hours each within the normal English class. Learners were asked their degrees of receptive and productive knowledge of the target words using the Vocabulary Knowledge Scale (Paribakht \& Wesche, 1997). The researcher administered a pre-test (50 target words) before the treatment to corroborate that these words were not known. Post-test and delayed test (after the instruction period and again three months later) were conducted to provide information on the acquisition and retention of meaning of the unknown words.

Table 5. Breakdown responses over types of vocabulary knowledge for both groups (adapted from Min, 2008, p. 93)

\begin{tabular}{lllllll}
\hline \multicolumn{7}{c}{ Partially } \\
\hline Group & Test & Unknown & Known & Receptive & Productive & Total $^{1}$ \\
\hline RV & Pretest & $55.60 \%$ & $40.48 \%$ & $2.80 \%$ & $1.12 \%$ & $100 \%$ \\
& Acquisition & $1.2 \%$ & $26.32 \%$ & $35.12 \%$ & $37.36 \%$ & $100 \%$ \\
& Retention & $7.44 \%$ & $57.52 \%$ & $16.08 \%$ & $18.96 \%$ & $100 \%$ \\
\hline NR & Pretest & $49.44 \%$ & $46.48 \%$ & $2.08 \%$ & $2.00 \%$ & $100 \%$ \\
& Acquisition & $4.64 \%$ & $46.08 \%$ & $28.96 \%$ & $20.32 \%$ & $100 \%$ \\
& Retention & $10.32 \%$ & $63.60 \%$ & $13.76 \%$ & $12.32 \%$ & $100 \%$ \\
\hline
\end{tabular}

Note. ${ }^{1}$ Total number of responses $=1,250$.

The three measurement periods were analysed with $t$-tests which indicated that the instruction given to the experimental group had a positive and significant effect than their control counterparts $(t=9.08, p<.01)$ at the time of acquisition and $(t=5.10, p<.01)$ at the time of retention. The results of the receptive and productive vocabulary knowledge tests are presented in Table 5 above.

The findings showed that the learners who had the treatment made gains of $32.32 \%$ in receptive word knowledge and of $36.24 \%$ in productive word knowledge. Despite the fact that the control group acquired a large amount of vocabulary, it made less gain of $26.88 \%$ in receptive word knowledge and of $18.32 \%$ in productive word knowledge. Consequently, we can say that the instructional treatment helped to improve certain aspects of word knowledge such as recognition and production incrementally and simultaneously over time.

\section{Conclusion}

This paper comprises reviews and discussions of relevant studies concerning the incremental nature of vocabulary acquisition. Learners' size of their SL/FL vocabulary gradually develops in a number of ways, with multiple exposures to target words enhancing the process. We can infer that vocabulary learning is not limited to the meaning facet of word knowledge and that other facets of lexical knowledge are part of the learning process. This implies that the description of vocabulary knowledge based on the meaning aspect is not accurate and does not do justice to the complexity of word knowledge. We have seen that the mastery of word knowledge is best seen as being on a continuum, both overall as well as in respect of single word knowledge. Moreover, this knowledge involves recognizing the word when it is read or heard (receptive knowledge) or being able to use it in writing or speaking (productive knowledge). We have also discussed how the level of mastery of receptive and productive knowledge can vary, thus providing evidence of the gradual and complicated nature of the process of vocabulary acquisition. The inconsistency of the degrees of knowledge between the receptive and productive forms often stems from the lack of conceptualisation of what receptive and productive mastery of word entails. The issue of drawing a line between receptive and productive knowledge has been raised but research has not yet been able to come to any conclusion. That is it is still unknown what type and amount of vocabulary knowledge are necessary to push the language learners to the productive level of mastery.

\section{References}

Baudot, J. (1992). Fréquences d'utilisation des mots en français écrit contemporain. Presses de l'Université de 
Montréal.

Channell, J. (1988). Psycholinguistic considerations in the study of L2 vocabulary acquisition. In R. Carter \& M. McCarthy (Eds.), Vocabulary and Language Teaching, 83-96.

Gallego, M. T., \& Llach, M. P. A. (2009). Exploring the increase of receptive vocabulary knowledge in the foreign language: A longitudinal study. International Journal of English Studies, 9(1), 113-133.

Henriksen, B. (1999). Three dimensions of vocabulary development. Studies in Second Language Acquisition, 21(2), 303-317. http://dx.doi.org/10.1017/S0272263199002089

Hirsch, E. (2003). Reading comprehension requires knowledge - of words and the world. American Educator, $27(1), 10-13$.

Hunt, A., \& Beglar, D. (2005). A framework for developing EFL reading vocabulary. Reading in a Foreign Language, 17(1), 23-59.

Joe, A. (2010). The quality and frequency of encounters with vocabulary in an English for Academic Purposes programme. Reading in a Foreign Language, 22(1), 117-138.

Laufer, B. (1998). The development of passive and active vocabulary in a second language: Same or different? Applied Linguistics, 19(2), 255-271. http://dx.doi.org/10.1093/applin/19.2.255

Laufer, B., \& Nation, P. (1995). Vocabulary size and use: Lexical richness in L2 written production. Applied Linguistics, 16(3), 307-322. http://dx.doi.org/10.1093/applin/16.3.307

Laufer, B., \& Nation, P. (1999). A vocabulary-size test of controlled productive ability. Language Testing, 16(1), 33-51. http://dx.doi.org/10.1177/026553229901600103

Meara, P. (1996). The dimensions of lexical competence. Performance and competence in second language acquisition. Cambridge: Cambridge University Press, 35-35.

Melka, F. (1997). Receptive vs. productive aspects of vocabulary. In N. Schmitt \& M. McCarthy (Eds.), Vocabulary: Description, acquisition and pedagogy (pp. 84-102). New York, NY: Cambridge University Press.

Milton, J. (2006). Language lite? Learning French vocabulary in school. Journal of French Language Studies, 16(2), 187-205. http://dx.doi.org/10.1017/S0959269506002420

Min, H. T. (2008). EFL vocabulary acquisition and retention: Reading plus vocabulary enhancement activities and narrow reading. Language $\quad$ Learning, $\quad 58(1), \quad 73-115$. http://dx.doi.org/10.1111/j.1467-9922.2007.00435.x

Nagy, W. E., \& Scott, J. A. (2000). Vocabulary processes. Handbook of Reading Research, 3, $269-284$.

Nagy, W. E., Anderson, R. C., \& Herman, P. A. (1987). Learning word meanings from context during normal reading. American Educational Research Journal, 237-270. http://dx.doi.org/10.3102/00028312024002237

Nation, I. S. P. (1983). Testing and teaching vocabulary. Guidelines, 5, 12-25.

Nation, I. S. P. (1990). Teaching and learning vocabulary. New York, NY: Heinle \& Heinle.

Nation, I. S. P. (2001). Learning vocabulary in another language. Cambridge: Cambridge University Press. http://dx.doi.org/10.1017/CBO9781139524759

Paribakht, T. S., \& Wesche, M. (1997). Vocabulary enhancement activities and reading for meaning in second language vocabulary acquisition. In J. Coady \& T. Huckin (Eds.), Second language vocabulary acquisition: A rationale for pedagogy (pp. 174-200). Cambridge: Cambridge University Press.

Pigada, M., \& Schmitt, N. (2006). Vocabulary acquisition from extensive reading: A case study. Reading in a Foreign Language, 18(1), 1-28.

Qian, D. D. (1999). Assessing the roles of depth and breadth of vocabulary knowledge in reading comprehension. Canadian Modern Language Review/La revue canadienne des langues vivantes, 56(2), $282-308$. http://dx.doi.org/10.3138/cmlr.56.2.282

Qian, D. D. (2002). Investigating the relationship between vocabulary knowledge and academic reading performance: An assessment perspective. Language Learning, 52(3), 513-536. http://dx.doi.org/10.1111/1467-9922.00193

Qian, D. D., \& Schedl, M. (2004). Evaluation of an in-depth vocabulary knowledge measure for assessing 
reading performance. Language Testing, 21(1), 28-52. http://dx.doi.org/10.1191/0265532204lt273oa

Read, J. (2000). Assessing vocabulary. Cambridge: Cambridge University Press. http://dx.doi.org/10.1017/CBO9780511732942

Richards, J. C. (1976). The role of vocabulary teaching. TESOL Quarterly, (10), 77-89. http://dx.doi.org/10.2307/3585941

Schmitt, N. (1998). Tracking the incremental acquisition of second language vocabulary: A longitudinal study. Language Learning, 48(2), 281-317. http://dx.doi.org/10.1111/1467-9922.00042

Schmitt, N. (2000). Vocabulary in language teaching. Cambridge: Cambridge University Press.

Schmitt, N. (2010). Researching vocabulary: A vocabulary research manual. New York, NY: Palgrave Macmillan. http://dx.doi.org/10.1057/9780230293977

Schmitt, N., Schmitt, D., \& Clapham, C. (2001). Developing and exploring the behavior of two new versions of the Vocabulary Levels Test. Language Testing, 18(1), 55-88.

Stahl, S. A. (Ed.). (2009). Words are learned incrementally over multiple exposures: International Reading Association.

Waring, R. (1997). A study of receptive and productive learning from word cards. Studies in Foreign Languages and Literature, 21(1), 94-114.

Webb, S. (2005). Receptive and productive vocabulary learning. Studies in Second Language Acquisition, 27(1), 33-52. http://dx.doi.org/10.1017/S0272263105050023

Webb, S. (2007). The effects of repetition on vocabulary knowledge. Applied Linguistics, 28(1), 46-65. http://dx.doi.org/10.1093/applin/aml048

\section{Copyrights}

Copyright for this article is retained by the author(s), with first publication rights granted to the journal.

This is an open-access article distributed under the terms and conditions of the Creative Commons Attribution license (http://creativecommons.org/licenses/by/3.0/). 